\title{
Unravelling the role of Mesenchymal Stem/Stromal Cells Secretome in intervertebral disc degeneration in a pro-inflammatory/degenerative ex vivo model
}

JR Ferreira

i3S/INEB/ICBAS

GQ Teixeira

i3S/INEB/ICBAS/Institute of Orthopaedic Research and Biomechanics, University of Ulm

E Neto

i3S/INEB

C Ribeiro-Machado

i3S/INEB

AM Silva

i3S/INEB/ICBAS/AstraZeneca R\&D Gothemburg

J Caldeira

i3S/INEB

C Leite Pereira

i3S/INEB

$S$ Bidarra

i3S/INEB

AF Maia

i3S/IBMC

$M$ Lamghari

i3S/INEB/ICBAS

MA Barbosa

i3S/INEB/ICBAS

RM Gonçalves ( $\square$ raquelg@ineb.up.pt )

https://orcid.org/0000-0003-2841-0485

Research article

Keywords: Mesenchymal Stem Cells, Degenerative Intervertebral Discs, Immunomodulation, Secretome, Paracrine signalling, Extracellular matrix

Posted Date: August 17th, 2020 
DOI: https://doi.org/10.21203/rs.2.22688/v2

License: (c) (1) This work is licensed under a Creative Commons Attribution 4.0 International License. Read Full License 
The authors have withdrawn this preprint from Research Square 